\title{
Private treatment fee setting in general dental practice
}

\author{
Factors affecting fee setting for private treatment in general dental practice
}

J. Kabir and A. C. Mellor Br Dent J 2004; 197: 200-203

\section{Objective}

To examine how pricing policies were contrived in general dental practice in terms of fee-for-item and hourly rate and how these were affected by specialist status and the level of private care provided in a practice.

\section{Design}

A postal questionnaire.

Subjects

Members of the British Society for General Dental Surgery working in dental practice.

\section{Results}

Out of 160 eligible members, responses were received from 124 members (78\%). Fifty-seven respondents claimed to specialise in one or more fields of dentistry. The majority of respondents consulted fellow colleagues or partners for advice on fee setting. A minority took external advice. The charging method varied according to the item of treatment with fee-for-item used predominantly for items such as a new patient examination, and hourly rate used more for items such as a direct composite restoration. Seventy-one respondents stated that their practice was $80-100 \%$ private treatment and these practitioners were significantly more likely to charge by hourly rate than fee-for-item for many items of treatment. Specialist status did not have any effect on charging method. The most important factors related to the setting of fees-for-item or hourly rate were clinical time spent, practice overheads and laboratory costs.

\section{Conclusions}

This project has taken the views of a large group of experienced general dental practitioners, many of whom work purely in the private sector. The most important factors affecting fee setting were clinical time, practice overheads and laboratory costs. The method of charging was most affected by the proportion of private treatment provided by the practice.

\section{IN BRIEF}

A group of UK general practitioners was approached for their strategies on fee setting.

- Dentists charge by hourly rate or fee-for-item according to the item of treatment.

- Clinical time spent is the most important factor in setting fees.

- The proportion of private treatment provided by a practice is a factor in whether fee-for-item or hourly rate is most used for fee setting.

\section{COMMENT}

In this study, the authors have investigated how general dental practitioners establish pricing policies when undertaking privately funded treatment. They used a postal questionnaire to obtain feedback from a selected group of 160 practitioners and obtained a $78 \%$ response although there was a high non-response rate from the dentists qualifying after 1981(39\%). Eighty-two per cent stated that they took advice when deciding on a pricing structure but interestingly only a small minority obtained external advice from financial consultants, the BDA or GDPA. The authors investigated the charging structures for several different items of treatment and found that fee-for-item (FFI) was more than twice as popular for new patient examinations than charging an hourly rate. There was greater variation for individual items of treatment such as a direct placement anterior composite (40\% FFI and 38\% hourly rate) and metal-ceramic crown (57\% FFI and $13 \%$ hourly rate). In the sample selected, $57 \%$ stated that their practice involved more than $80 \%$ private treatment. Those in this group indicated a preference for charging on an hourly rate rather than FFI particularly for direct posterior composite restorations. In determining the hourly rate, practice overheads were considered to be a very important factor by $77 \%$ of the sample, whereas dentist specialisation, practice ownership and rates of other dentists locally were considered to be of less importance. The greatest influences on the calculation of the fee-per-item were the hourly rate, the laboratory costs and the clinical time required. The study suggests that for this sample, fee pricing was not heavily influenced by competition from local practitioners.

This area of study is of increasing relevance. Firstly because there has been a dramatic increase in the provision of private dental care in the UK. In 1993, 25\% of GDPs earned 25-100\% of their income from private treatment but by 2002 this was estimated to have risen to $46 \% .{ }^{1}$ Secondly, the public and the Office of Fair Trading have recently expressed some concerns relating to the transparency of fee pricing for private dental care and thirdly because there is very little data available in the area of fee setting. The authors have opened up an important and timely area of research which demands further attention for the benefit of both the public and the profession.

\section{R. S. Ireland, Honorary Senior Research Fellow}

The University of Liverpool

doi:10.1038/sj.bdj.4811581

1. Policy Bulletin: Issue one. London: British Dental Association, April 2003. 